\title{
Congestive heart failure complicating aortic regurgitation with medical and surgical management: A prospective study of traditional and quantitative echocardiographic markers
}

Delphine Detaint, MD, ${ }^{\mathrm{a}}$ Joseph Maalouf, MD, ${ }^{\mathrm{a}}$ Christophe Tribouilloy, MD, ${ }^{\mathrm{a}}$ Douglas W. Mahoney, MS, ${ }^{\mathrm{b}}$ Hartzell V. Schaff, MD, ${ }^{\mathrm{c}}$ A. Jamil Tajik, MD, ${ }^{a}$ and Maurice Enriquez-Sarano, MD $^{\mathrm{a}}$

Objective: Congestive heart failure complicating aortic regurgitation is poorly described, and predictive roles of quantitative versus traditional (symptoms or low ejection fraction) surgical markers are unclear.

Methods: We prospectively enrolled 287 patients with aortic regurgitation (age, $61 \pm 17$ years; 68\% male) in whom we performed quantitative Doppler echocardiographic analysis and personal physicians conducted management.

Results: After diagnosis, 40 congestive heart failure episodes occurred under medical management (10-year, $23 \% \pm 4 \%$ ) causing high subsequent mortality (hazard ratio [HR], 2.8; 95\% confidence interval [CI], $1.2-$ $6.8 ; P=.02$ ). Patients with traditional surgical markers (symptoms or ejection fraction $<50 \%$ ) were surprisingly followed $1.4 \pm 3.3$ years under medical management with frequent congestive heart failure (adjusted risk, 4.9; 95\% CI, 2.1-11.0; $P<.001)$ and excess postoperative mortality (HR, 3.0; 95\% CI, 1.3-7.1; $P=.01)$. Quantitative American Society of Echocardiography aortic regurgitation grading and left ventricular end-systolic volume index independently predicted congestive heart failure (quantitative American Society of Echocardiography severe aortic regurgitation: $\mathrm{HR}, 3.6 ; 95 \% \mathrm{CI}, 1.3-13.0 ; P=.015$; end-systolic volume index $\geq 45 \mathrm{~mL} / \mathrm{m}^{2}$ : HR, 2.1; 95\% CI, 1.03-4.4; $P=.04)$ or death-congestive heart failure with incremental predictive value $(P<$ .001). Higher congestive heart failure rates occurred with quantitative American Society of Echocardiography severe aortic regurgitation (regurgitant volume of $\geq 60 \mathrm{~mL} /$ beat or orifice of $\geq 30 \mathrm{~mm}^{2}$ ) versus quantitative American Society of Echocardiography mild aortic regurgitation (10-year: 44\% $\pm 10 \%$ vs $15 \% \pm 7 \%, P<.001)$ and end-systolic volume index of $45 \mathrm{~mL} / \mathrm{m}^{2}$ or greater versus less than $45 \mathrm{~mL} / \mathrm{m}^{2}(33 \% \pm 7 \%$ vs $9 \% \pm 2 \%$, $P<.001$ ). Traditional markers (symptoms and ejection fraction $<50 \%$ ) had lower sensitivity for congestive heart failure than quantitative echocardiography (all $P<.001$ ). Cardiac surgery for aortic regurgitation markedly reduced congestive heart failure in quantitative American Society of Echocardiography severe aortic regurgitation (HR, $0.23 ; 95 \%$ CI, $0.08-0.68 ; P=.008)$ without excess mortality $(P=.10)$.

Conclusion: This prospective study of aortic regurgitation shows frequent congestive heart failure under conservative management. Traditional surgical markers (symptoms and ejection fraction $<50 \%$ ) predict subsequent congestive heart failure but are insensitive, and rescue operations are often delayed and associated with excess mortality. Quantitative echocardiography provides congestive heart failure predictors that are independent, incremental, and more sensitive than traditional markers. Cardiac surgery for aortic regurgitation markedly reduces congestive heart failure rates in high-risk patients with aortic regurgitation.

Congestive heart failure $(\mathrm{CHF})$ is a dreaded complication of cardiac disease, which remains challenging in valvular heart disease despite the availability of valvular surgery. ${ }^{1}$ In patients with aortic regurgitation (AR), data regarding $\mathrm{CHF}$ are sketchy and discordant, leaving doubts regarding its rates

From the Division of Cardiovascular Diseases and Internal Medicine, ${ }^{\mathrm{a}}$ the Section of Biostatistics, ${ }^{\mathrm{b}}$ and the Division of Cardiovascular Surgery, ${ }^{\mathrm{c}}$ Mayo Clinic, Rochester, Minn.

Supported in part by grant HL 64928 from the National Institutes of Health. Dr Detaint was supported by a grant from the French Federation of Cardiology.

Received for publication March 21, 2008; revisions received June 10, 2008; accepted for publication July 22, 2008.

Address for reprints: Maurice Enriquez-Sarano, MD, Mayo Clinic, 200 First Street SW, Rochester, MN 55905 (E-mail: Sarano.maurice@mayo.edu).

J Thorac Cardiovasc Surg 2008;136:1549-57

$0022-5223 / \$ 34.00$

Copyright $₫ 2008$ by The American Association for Thoracic Surgery

doi:10.1016/j.jtcvs.2008.07.036 and determinants. ${ }^{2-5}$ Uncertainties were amplified by a lack of specific AR severity measures. ${ }^{6}$ Limited data suggest poor outcome after $\mathrm{CHF}$ in patients with $\mathrm{AR} .^{7,8}$ Thus defining patients' subsets at high CHF risk is crucial to the riskstratification process.

In clinical guidelines risk stratification in AR is essentially based on symptoms or reduced ventricular function., These traditional surgical markers play a central role because they are considered the strongest predictors of outcome. ${ }^{2}$ However, when surgical intervention is performed with these traditional markers, symptoms usually improve, but surgical series suggest that survival might remain suboptimal. ${ }^{10,11}$ These dubious outcomes warrant new risk-stratification tools to provide better outcomes.

Quantitative echocardiography codified by the American Society of Echocardiography (quantitative American Society of Echocardiography [QASE] grading) ${ }^{6}$ might play an 


$$
\begin{aligned}
& \text { Abbreviations and Acronyms } \\
& \begin{aligned}
\mathrm{AR} & =\text { aortic regurgitation } \\
\mathrm{CHF} & =\text { congestive heart failure } \\
\mathrm{CI} & =\text { confidence interval } \\
\mathrm{EF} & =\text { ejection fraction } \\
\mathrm{ERO} & =\text { effective regurgitant orifice } \\
\mathrm{ESVI} & =\text { end-systolic volume index } \\
\mathrm{HR} & =\text { hazard ratio } \\
\mathrm{LV} & =\text { left ventricular } \\
\mathrm{QASE} & =\text { quantitative American Society of } \\
& \text { Echocardiography } \\
\text { RVol } & =\text { regurgitant volume }
\end{aligned}
\end{aligned}
$$

important role in AR. For this purpose, we conducted a prospective study in patients with quantified AR and ventricular volumes using Doppler echocardiography. Pilot data from the asymptomatic segment of this study were encouraging by showing a link between these novel variables and the combined end point of cardiac events. ${ }^{12}$ However, clinically relevant issues are whether these quantitative echocardiographic variables specifically predict $\mathrm{CHF}$ occurrence and have an incremental role over symptoms and ejection fraction $(\mathrm{EF})$ and whether these various types of predictors affect not only medical but also surgical outcome. ${ }^{13}$ Thus we hypothesized that $\mathrm{CHF}$ is frequent in AR treated medically and that quantitative echocardiography independently and incrementally (over symptoms and EF) predicts $\mathrm{CHF}$ and defines high-risk groups. We also hypothesized that surgical intervention for AR reduces the risk of CHF, with excellent survival in the quantitatively defined high-risk subsets.

\section{MATERIALS AND METHODS \\ Study Population}

The study was approved by the institutional review board, and patients were consecutively and prospectively enrolled after oral consent between 1990 and 2003 (1) if they had AR that was at least mild, as determined by means of standard color flow imaging ${ }^{14}$; (2) if they had AR that was pure (no stenosis) and isolated (no other valve disease); and (3) if they underwent quantitative echocardiography performed by the investigators with measurement of AR degree and left ventricular (LV) volumes. Exclusion criteria were (1) aortic dissection or ongoing endocarditis; (2) functional AR caused by hypertension; (3) associated aortic systolic gradient of 20 $\mathrm{mm} \mathrm{Hg}$ or greater; (4) concomitant mitral, congenital (other than bicuspid valve), or pericardial disease; or (5) previous valve repair or replacement.

\section{Clinical Evaluation and Management}

Patients were evaluated and treated by their independent personal physicians who assessed symptoms, were informed of all results, and made all management decisions (without interference from investigators). Followup, collected after closure of enrollment and of all baseline data-collection procedures, was complete up to death or 2006 in $95 \%$ of patients and was less than 1 year in only $1.7 \%$ of patients. CHF ascertainment used Framingham criteria, ${ }^{15}$ and documentation of patients' clinical events was reviewed to assess these criteria. Symptoms alone were not sufficient for CHF diag- nosis, and congestive manifestations were required. Comorbidity assessment used the Charlson index. ${ }^{16}$

\section{Doppler Echocardiographic Analysis}

Quantitation of AR. Comprehensive AR quantitation used 3 validated methods that were eventually averaged to calculate both regurgitant volume (RVol) and effective regurgitant orifice (ERO) area (85\% of patients had 2 or 3 methods). These were quantitative Doppler scanning based on aortic and mitral stroke volume measurement, ${ }^{17,18}$ quantitative 2-dimensional echocardiography based on LV and mitral stroke volume, ${ }^{18,19}$ and a proximal isovelocity surface area method analyzing proximal flow convergence. ${ }^{20}$ QASE guidelines regarding AR grading ${ }^{6}$ define QASE severe AR as an RVol of $60 \mathrm{~mL} /$ beat or greater or an ERO area of $30 \mathrm{~mm}^{2}$ or greater, QASE mild AR as both an RVol of less than $30 \mathrm{~mL} /$ beat and an ERO area of less than $10 \mathrm{~mm}^{2}$, and QASE moderate AR as greater than mild criteria $\left(\mathrm{RVol} \geq 30 \mathrm{~mL} /\right.$ beat or ERO area $\geq 10 \mathrm{~mm}^{2}$ ) but not reaching QASE severe criteria. Color flow imaging jet width/LV outflow tract width ratio ${ }^{14}$ was also prospectively measured from parasternal long-axis views. ${ }^{6}$

LV assessment. LV end-diastolic and end-systolic volume indexes (ESVIs) and EF determined by using the Simpson disk method and LV mass were measured as recommended by the American Society of Echocardiography. ${ }^{19}$ LV diameters using M-mode echocardiography were measured as absolute values and normalized to body surface area.

\section{Statistical Analysis}

Data are presented as mean values \pm standard deviations or percentages. Group comparisons used analysis of variance or the $\chi^{2}$ test, as appropriate. The main outcome end point was CHF occurrence under medical management (censored at surgical intervention), and the entire follow-up after diagnosis was used to assess the effect of surgical intervention as a timedependent variable. Survival after surgical intervention was also analyzed. A secondary end point was combined CHF or death event. Event rates (estimated \pm standard error) with the Kaplan-Meier method were compared by using the log-rank test. Time to CHF (or CHF death) was analyzed by means of the Cox proportional hazard method, with calculation of risk ratio unadjusted and adjusted for age, sex, and comorbidity score. The main variables of interest in predicting CHF were baseline symptoms, EF, ESVI, and QASE AR grading.

\section{RESULTS}

\section{Baseline Characteristics}

The 287 patients enrolled in the cohort were followed for $7.7 \pm 4.0$ years. Their baseline characteristics are presented in Table 1. Some data on the asymptomatic segment of this population were previously presented. ${ }^{12}$ Symptoms at presentation were observed in $25(9 \%)$ patients, and LV dysfunction $(\mathrm{EF}<50 \%)$ was observed in $17(6 \%)$ patients. These 2 patient subsets had greater LV volume and mass and lower EF (all $P<.001$ ) but showed no difference in age (both $P>.22$ ), sex (both $P>.34$ ), or comorbidity (both $P>.49$ ) compared with the cohort remainder. Causes of AR were degenerative in $53 \%$, congenital in $22 \%$, aortic root dilatation in $12 \%$, chronic endocarditic lesions in $4 \%$, rheumatic in 3\%, and miscellaneous in 6\%. QASE grading ${ }^{1}$ was $18 \%$ QASE mild, $40 \%$ QASE moderate, and $42 \%$ QASE severe AR (Table 1). With higher grade, there were more symptoms, lower EF, and greater LV dilatation and hypertrophy and jet size (Table 1). Vasodilator therapies during medical follow-up were angiotensin-converting enzyme 
TABLE 1. Baseline characteristics of patients according to quantitative assessment of AR and their association with CHF under conservative management

\begin{tabular}{|c|c|c|c|c|c|c|}
\hline & \multirow[b]{2}{*}{$\begin{array}{c}\text { Overall population } \\
(\mathrm{n}=\mathbf{2 8 7}) \\
\end{array}$} & \multicolumn{4}{|c|}{ AR grading* } & \multirow[b]{2}{*}{$\begin{array}{c}\text { Association with } \\
\text { time to } C H F, P \text { valu } \\
\end{array}$} \\
\hline & & $\begin{array}{l}\text { QASE mild } \\
\quad(\mathrm{n}=\mathbf{5 2})\end{array}$ & $\begin{array}{l}\text { QASE moderate } \\
(\mathrm{n}=114)\end{array}$ & $\begin{array}{c}\text { QASE severe } \\
(\mathbf{n}=\mathbf{1 2 1})\end{array}$ & $\begin{array}{c}P \\
\text { value }\end{array}$ & \\
\hline \multicolumn{7}{|l|}{ Clinical characteristics } \\
\hline Age, y & $61 \pm 17$ & $63 \pm 15$ & $62 \pm 18$ & $59 \pm 18$ & .25 & .003 \\
\hline Male sex, no. $(\%)$ & $194(68)$ & $23(44)$ & $69(60)$ & $102(84)$ & $<.001$ & .12 \\
\hline Atrial fibrillation, no. $(\%)$ & $18(6)$ & $1(2)$ & $8(7)$ & $9(7)$ & .24 & .03 \\
\hline History of hypertension, no. $(\%)$ & $123(46)$ & $27(59)$ & $53(49)$ & $43(39)$ & .06 & .54 \\
\hline History of coronary artery disease, no. $(\%)$ & $44(16)$ & $8(15)$ & $17(15)$ & $19(16)$ & .99 & .02 \\
\hline Charlson comorbidity index, arbitrary units & $1.9 \pm 2.3$ & $1.4 \pm 2.0$ & $2.2 \pm 2.5$ & $1.9 \pm 2.3$ & .08 & .001 \\
\hline Symptoms, no. $(\%)$ & $25(9)$ & $0(0)$ & $2(2)$ & $23(19)$ & $<.001$ & $<.001$ \\
\hline \multicolumn{7}{|l|}{ Echocardiographic characteristics } \\
\hline Ejection fraction, $\%$ & $66 \pm 11$ & $70 \pm 9$ & $67 \pm 10$ & $64 \pm 11$ & .002 & $<.001$ \\
\hline End-systolic diameter index, $\mathrm{mm} / \mathrm{m}^{2}$ & $19 \pm 4$ & $17 \pm 3$ & $19 \pm 4$ & $21 \pm 5$ & $<.001$ & $<.001$ \\
\hline End-diastolic volume index, $\mathrm{mL} / \mathrm{m}^{2}$ & $109 \pm 29$ & $74 \pm 17$ & $114 \pm 22$ & $136 \pm 38$ & $<.001$ & $<.001$ \\
\hline End-systolic volume index, $\mathrm{mL} / \mathrm{m}^{2}$ & $39 \pm 22$ & $22 \pm 11$ & $33 \pm 18$ & $50 \pm 27$ & $<.001$ & $<.001$ \\
\hline Left ventricular mass, $\mathrm{g}$ & $257 \pm 80$ & $188 \pm 58$ & $235 \pm 73$ & $307 \pm 97$ & $<.001$ & $<.001$ \\
\hline \multicolumn{7}{|l|}{ AR parameters } \\
\hline Jet to outflow tract width ratio, $\%$ & $40 \pm 14$ & $27 \pm 12$ & $36 \pm 13$ & $50 \pm 16$ & $<.001$ & .13 \\
\hline Regurgitant volume, $\mathrm{mL} /$ beat & $57 \pm 22$ & $17 \pm 5$ & $41 \pm 12$ & $89 \pm 31$ & $<.001$ & $<.001$ \\
\hline Effective regurgitant orifice, $\mathrm{mm}^{2}$ & $26 \pm 12$ & $7 \pm 2$ & $18 \pm 6$ & $42 \pm 18$ & $<.001$ & $<.001$ \\
\hline
\end{tabular}

$A R$, Aortic regurgitation; $C H F$, congestive heart failure; $Q A S E$, quantitative American Society of Echocardiography. $* \mathrm{QASE}$ severe AR is defined as a regurgitant volume of $60 \mathrm{~mL} /$ beat or greater or an effective regurgitant orifice area of $30 \mathrm{~mm}^{2}$ or greater, QASE mild AR is defined as a regurgitant volume of less than $30 \mathrm{~mL} / \mathrm{beat}$ and an effective regurgitant orifice ara of less than $10 \mathrm{~mm}^{2}$, and QASE moderate AR is defined as regurgitation greater than QASE mild (regurgitant volume $\geq 30 \mathrm{~mL} /$ beat or effective regurgitant orifice $\geq 10$ $\mathrm{mm}^{2}$ ) but not reaching QASE severe criteria.

inhibitors in 116 patients, calcium-channel blockers in 58 patients, and angiotensin receptor blockers in 37 patients.

\section{CHF Rates and Determinants Under Medical Management}

Follow-up under conservative management was 1492 patient-years, with survival of $91 \% \pm 2 \%$ and $77 \% \pm 4 \%$ at 5 and 10 years, respectively. Remarkably, patients with symptoms or EF of less than $50 \%$ were followed for $1.4 \pm 3.3$ years under medical management. Reasons for deferral of surgical intervention were multiple but essentially reflected that patients were considered well or improved with medical treatment while patient preference and comorbidity seldom justified surgical delay. Under conservative management, 40 episodes of CHF occurred with 5- and 10-year rates of $15 \% \pm 2 \%$ and $23 \% \pm 4 \%$, respectively. CHF occurrence was associated with almost tripling of subsequent mortality (adjusted hazard ratio [HR], 2.8; 95\% confidence interval [CI], 1.2-6.8; $P=.02$ ).

Univariate baseline predictors of CHF under conservative management are listed in Table 1. Traditional surgical markers (symptoms and EF) were linked to CHF. Quantitative variables, ESVI (HR, 1.04; 95\% CI, 1.02-1.05 [per milliliter per square meter]; $P<.001$ ), RVol (HR, 1.19; 95\% CI, $1.10-1.29$ [per $10 \mathrm{~mL} /$ beat]; $P<.001$ ), and ERO area (HR, 1.49; 95\% CI, 1.25-1.72 [per $10 \mathrm{~mm}^{2}$ ]; $P<.001$ ) were also powerful univariate CHF predictors. Table 2 shows that AR quantitation predicted CHF (with or without adjustment) and that QASE severe versus QASE mild grading implied quadrupling of CHF risk. QASE moderate grading was not independently associated with CHF. Prediction of CHF by means of QASE grading was not affected by vasodilator therapy $(P<.004)$. The other independent determinants of CHF adjusting for age, sex, and comorbidity were symptoms $(P<.01)$ and LV dysfunction assessment based on either an EF of less than $50 \%(P<.001)$ or an ESVI of $45 \mathrm{~mL} / \mathrm{m}^{2}$ or greater $(P<.01)$.

Table 3 shows that adjusting for age, sex, and comorbidity and grouping traditional surgical indicators (symptoms or $\mathrm{EF}<50 \%$ ), quantitative variables, ESVI of $45 \mathrm{~mL} / \mathrm{m}^{2}$ or greater $(P=.04)$, and QASE severe $\mathrm{AR}(P=.015)$ independently predicted CHF under conservative management and provided incremental predictive power (overall $\chi^{2}$ increment $=17, P<.001$ ).

Five-year CHF rates under medical management were $65 \% \pm 17 \%$ with and $12 \% \pm 2 \%$ without traditional surgical indicators (symptoms or $\mathrm{EF}<50 \%, P<.001$ ); were $2 \% \pm 2 \%, 12 \% \pm 3 \%$, and $28 \% \pm 6 \%$ for QASE mild, moderate, or severe AR $(P<.001$, Figure 1); and were $33 \% \pm 7 \%$ with an ESVI of $45 \mathrm{~mL} / \mathrm{m}^{2}$ or greater and $9 \%$ $\pm 2 \%$ with an ESVI of less than $45 \mathrm{~mL} / \mathrm{m}^{2}(P<.001$, Figure 2).

History of clinical coronary disease and baseline atrial fibrillation were univariate $\mathrm{CHF}$ predictors but lost 
TABLE 2. CHF risk under conservative management associated with baseline regurgitant volume, effective regurgitant orifice area, and QASE severe $\mathbf{A R} *$

\begin{tabular}{|c|c|c|c|c|c|c|}
\hline \multirow[b]{2}{*}{ Models } & \multicolumn{2}{|c|}{ Regurgitant volume } & \multicolumn{2}{|c|}{ Effective regurgitant orifice } & \multicolumn{2}{|l|}{ QASE severe AR* } \\
\hline & Hazard ratio $(95 \% \mathrm{CI}) \dagger$ & $P$ value & Hazard ratio $(95 \% \mathbf{C I}) \ddagger$ & $P$ value & Hazard ratio $(\mathbf{9 5} \% \mathbf{C I}) \S$ & $P$ value \\
\hline Unadjusted & $1.19(1.1-1.3)$ & $<.001$ & $1.49(1.3-1.7)$ & $<.001$ & $5.7(2.2-19.8)$ & $<.001$ \\
\hline $\begin{array}{l}\text { Adjusted for age, sex, ESVI, NYHA, } \\
\text { comorbidity }\end{array}$ & $1.18(1.1-1.3)$ & .0015 & $1.35(1.1-1.3)$ & .004 & $4.3(1.4-16.4)$ & .009 \\
\hline $\begin{array}{l}\text { Adjusted for age, sex, EF, NYHA, } \\
\text { comorbidity }\end{array}$ & $1.24(1.1-1.4)$ & $<.001$ & $1.4(1.2-1.7)$ & $<.001$ & $5.9(2.1-21.4)$ & $<.001$ \\
\hline
\end{tabular}

$\overline{C H F}$, Congestive heart failure; $Q A S E$, quantitative American Society of Echocardiography; $A R$, aortic regurgitation; $95 \% C I, 95 \%$ confidence interval; $E S V I$, end-systolic volume index; NYHA, New York Heart Association; EF, ejection fraction. *QASE severe AR is defined as a regurgitant volume of $30 \mathrm{~mL} / \mathrm{beat}$ or greater or an effective regurgitant orifice area of $20 \mathrm{~mm}^{2}$ or greater, QASE mild AR is defined as a regurgitant volume of less than $30 \mathrm{~mL} /$ beat and an effective regurgitant orifice area of less than $10 \mathrm{~mm} \mathrm{~m}^{2} . \dagger$ Per $10-\mathrm{mL} /$ beat increment. $\ddagger$ Per $10-\mathrm{mm}^{2}$ increment. $§$ Using QASE mild AR grading as comparison.

significance in multivariate analysis and did not affect RVol, ERO area, QASE severe grading, and ESVI prediction (all $P<.01)$.

For the combined end point of death-CHF (the endpoint of $\mathrm{CHF}$ or death) under conservative management (68 events), traditional surgical indicators (symptoms or $\mathrm{EF}$ $<50 \%$; HR, 2.9; 95\% CI, 1.3-5.8; $P=.01$ ), ESVI of 45 $\mathrm{mL} / \mathrm{m}^{2}$ or greater (HR, $\left.1.9 ; 95 \% \mathrm{CI}, 1.1-3.4 ; P=.02\right)$, and QASE severe AR (HR, 3.1; 95\% CI, 1.4-7.3; $P=$ $.004)$ were independent predictors. Addition of quantitative echocardiographic variables provided incremental power $\left(\right.$ model $\chi^{2}$ increment $\left.=21, P<.001\right)$.

\section{Predictive Value of Quantitative Versus Traditional CHF Markers}

Yearly CHF rates and numbers of events are displayed for traditional indicators (symptoms and $\mathrm{EF}<50 \%$ ) in Figure 3 and for newer quantitative parameters (QASE grade and ESVI $\geq 45 \mathrm{~mL} / \mathrm{m}^{2}$ ) in Figure 4. Patients with baseline symptoms (Figure 3 ) had high CHF yearly rates (43.2 vs 2.5 per 100 patient-years, $P<.001$ ), contrasting with small number of CHF events predicted ( $\mathrm{n}=5,12.5 \%$ of CHF events). In contrast, QASE grading (Figure 4) shows less impressive difference in CHF rates (6.7 vs 2.0 vs 1.0 per 100 patient- years for QASE severe versus moderate versus mild AR, $P<.001$ ), but most CHF events are detected by QASE severe AR grading ( $\mathrm{n}=22,55 \%$ of CHF events). Thus symptoms showed higher specificity $(P<.001)$, and QASE grading showed higher sensitivity $(P<.001)$. Similarly, an EF of less than $50 \%$ was associated with high CHF rates (20.7 vs 2.7 per 100 patient-years, $P<.001$ ) but detected only $15 \%$ of CHF episodes (Figure 3 ), whereas an ESVI of $45 \mathrm{~mL} / \mathrm{m}^{2}$ or greater was associated with a less striking difference in CHF rates (8.5 vs 1.6 per 100 patientyears, $P<.001)$ but detected most CHF episodes $(52.5 \%$, Figure 4). Thus an EF of less than $50 \%$ had higher specificity $(P<.001)$, and an ESVI of $45 \mathrm{~mL} / \mathrm{m}^{2}$ or greater had a higher sensitivity $(P<.001)$. Patients with both QASE severe AR and an ESVI of $45 \mathrm{~mL} / \mathrm{m}^{2}$ or greater incurred frequent $\mathrm{CHF}(48 \% \pm 10 \%$ at 5 years and $69 \% \pm 13 \%$ at 10 years or $14.4 \%$ per 100 patient-years) close to that of patients with symptoms or low EF.

Traditional AR measures (jet-width ratio by means of color flow imaging ${ }^{6}$ and LV end-systolic diameter normalized or not to body surface area ${ }^{2,21}$ ) univariately predicted CHF under conservative management (all $P<.001$ ) but lost significance when adjusting for quantitative AR grading, the significance of which remained unaffected (all

TABLE 3. CHF risk under conservative management associated with traditional surgical markers, ESVI of $45 \mathrm{~mL} / \mathrm{m}^{2}$ or greater, and QASE severe AR

\begin{tabular}{|c|c|c|c|c|c|c|}
\hline \multirow[b]{2}{*}{ Models } & \multicolumn{2}{|c|}{$\begin{array}{c}\text { Traditional surgical } \\
\text { markers (symptoms or } \mathbf{E F}<\mathbf{5 0} \% \text { ) }\end{array}$} & \multicolumn{2}{|c|}{ ESVI $\geq 45 \mathrm{~mL} / \mathrm{m}^{2}$} & \multicolumn{2}{|c|}{ QASE severe AR* } \\
\hline & Hazard ratio $(95 \%$ CI $)$ & $P$ value & Hazard ratio $(95 \%$ CI $)$ & $P$ value & Hazard ratio $(95 \%$ CI $)$ & $P$ value \\
\hline Unadjusted & $1.18(1.1-1.3)$ & $<.001$ & $4.6(2.5-8.7)$ & $<.001$ & $5.7(2.2-19.8)$ & $<.001$ \\
\hline $\begin{array}{l}\text { Adjusted for age, sex, } \\
\text { comorbidity }\end{array}$ & $8.3(3.7-17.6)$ & $<.001$ & $3.9(2.0-7.8)$ & $<.001$ & $5.4(1.9-19.5)$ & $<.001$ \\
\hline Fully adjusted model $\dagger$ & $4.9(2.1-11.0)$ & $<.001$ & $2.1(1.03-4.4)$ & .04 & $3.6(1.3-13.0)$ & .015 \\
\hline$\chi^{2}$ Increment $\ddagger$ & 21 & $<.001$ & 6 & .02 & 11 & .005 \\
\hline
\end{tabular}




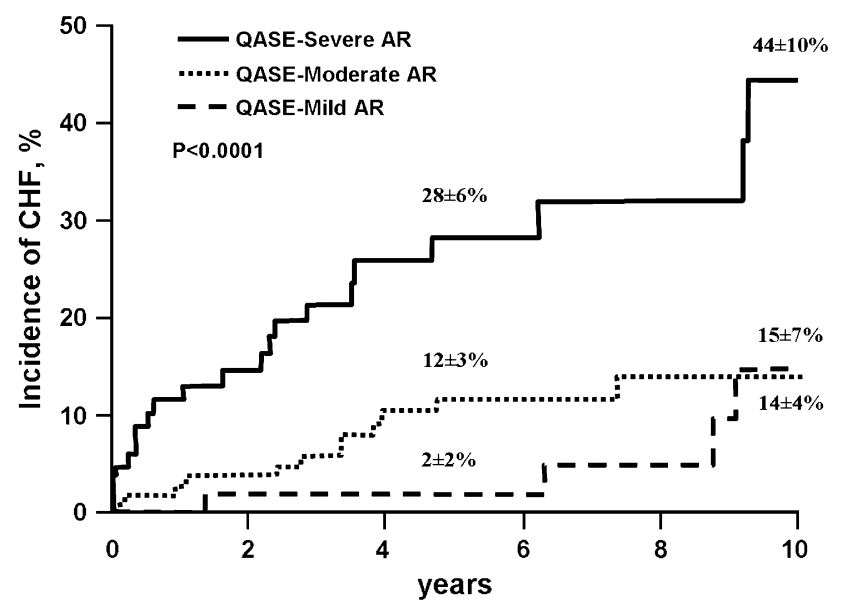

FIGURE 1. Congestive heart failure $(\mathrm{CHF})$ event rates after the diagnosis of aortic regurgitation $(A R)$ under medical management according to quantitative American Society of Echocardiography $(Q A S E)$ AR grading. QASE severe $A R$ is defined as a regurgitant volume of $60 \mathrm{~mL} /$ beat or greater or an effective regurgitant orifice area of $30 \mathrm{~mm}^{2}$ or greater, QASE mild AR is defined as a regurgitant volume of less than $30 \mathrm{~mL} /$ beat and an effective regurgitant orifice area of less than $10 \mathrm{~mm}^{2}$, and QASE moderate AR is defined as greater than QASE mild criteria (regurgitant volume $\geq 30 \mathrm{~mL} /$ beat or effective regurgitant orifice area $\geq 10 \mathrm{~mm}^{2}$ ) but not reaching QASE severe criteria. The numbers associated with each curve indicate the 5-year and 10-year CHF rate \pm standard error.

models $P<.03$ ). Traditional variables were less sensitive than QASE grading (all $P<.001$ ) and ESVI (all $P<$ .001). For death or CHF under conservative management, quantitative echocardiography had incremental sensitivity over traditional surgical indicators (symptoms or EF $<50 \%, 11 / 68$ events [16\%]) of an ESVI of $45 \mathrm{~mL} / \mathrm{m}^{2}$ or greater $(28 / 68$ events $[41 \%], P<.001)$ and QASE severe AR (30/68 events [44\%], $P<.001)$.

\section{Cardiac Surgery and Clinical Outcome}

A total of 106 patients underwent cardiac surgery for AR during follow-up for symptoms in 56 patients, LV dysfunction in 16 patients, aortic dilatation in 14 patients, endocarditis in 4 patients, and physician/patient preference in 16 patients. After surgical intervention for AR, 24 deaths were noted, with a 5 -year survival of $83 \% \pm 4 \%$. Adjusting for age, sex, and comorbidity, symptoms or an EF of less than $50 \%$ at diagnosis was associated with excess postoperative mortality (HR, 3.0; 95\% CI, 1.3-7.1; $P=.01)$. Fiveyear postoperative survival was $63 \% \pm 10 \%$ with traditional surgical markers at diagnosis versus $89 \% \pm$ $4 \%$ without $(P<.001)$. Conversely, a preoperative ESVI of $45 \mathrm{~mL} / \mathrm{m}^{2}$ or greater $(P=.09)$ or QASE severe AR $(P=.10)$ was not independently associated with excess postoperative mortality.

During 710 patient-years after surgical intervention, 6 episodes of CHF occurred so that surgical intervention

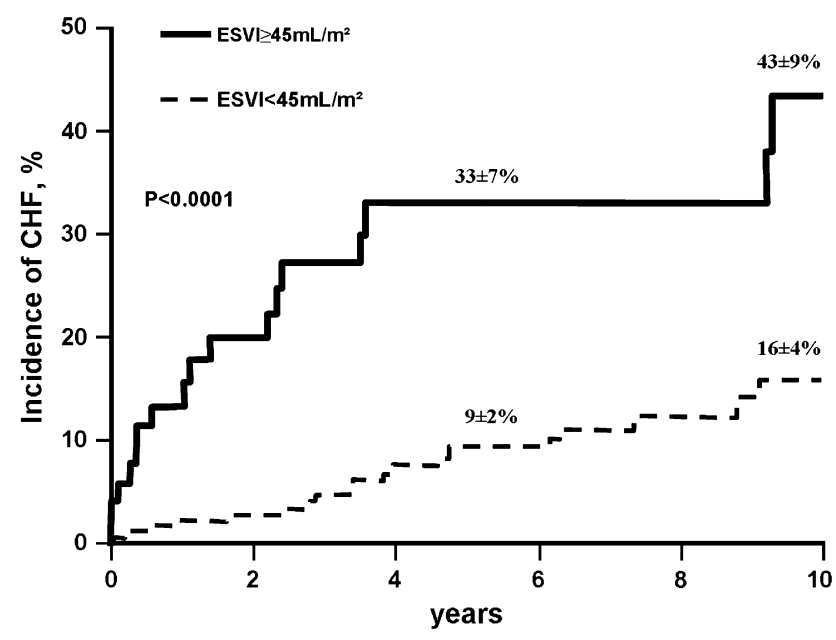

FIGURE 2. Congestive heart failure $(\mathrm{CHF})$ event rates after the diagnosis of aortic regurgitation under medical management according to the left ventricular end-systolic volume index (ESVI; $<45$ or $\geq 45 \mathrm{~mL} / \mathrm{m}^{2}$ ). The numbers associated with each curve indicate the 5 -year and 10 -year CHF rate \pm standard error.

as a time-dependant variable (accounting for time to operation) decreased CHF risk for patients with QASE severe $\mathrm{AR}$ (linearized yearly rate of $\mathrm{CHF}=6.7 \%$, decreasing to $0.9 \%$; HR, $0.23 ; 95 \%$ CI, $0.08-0.68 ; P=.008$ ). Conversely, in patients with QASE moderate AR, there was no detectable CHF difference $(P=.84)$. Adjusting for age, sex, symptoms, comorbidity, LV function, and QASE AR grading, surgical intervention for AR markedly reduced CHF (adjusted HR, 0.14; 95\% CI, 0.05-0.41; $P=.0003)$.

\section{DISCUSSION}

The present prospective cohort of patients with AR shows that CHF is frequent after AR diagnosis and is associated with excess subsequent mortality. In routine clinical practice, despite the presence of traditional surgical markers (symptoms or $\mathrm{EF}<50 \%$ ) in patients with age and comorbidity similar to those of our entire cohort, surgical intervention is often delayed, resulting in high rates of CHF and death-CHF under medical management. Also worrisome is the association of traditional surgical markers with excess mortality after surgical intervention. In contrast, novel quantitative markers (QASE AR grading and ESVI $\geq 45$ $\mathrm{mL} / \mathrm{m}^{2}$ ) have distinctive clinical value as independent CHF predictors under medical management. Patients with QASE severe AR (RVol $\geq 60 \mathrm{~mL} /$ beat or ERO $\left.\geq 30 \mathrm{~mm}^{2}\right)$ incur CHF 3 to 6 times more frequently than with QASE mild AR, and QASE grading superseded traditional markers of severe AR (color jet assessment and LV diameters). Patients with ESVIs of $45 \mathrm{~mL} / \mathrm{m}^{2}$ or greater incur doubling of CHF risk. Importantly, symptoms and EF of less than 50\% are specific, with very high rates of subsequent $\mathrm{CHF}(>20$ 

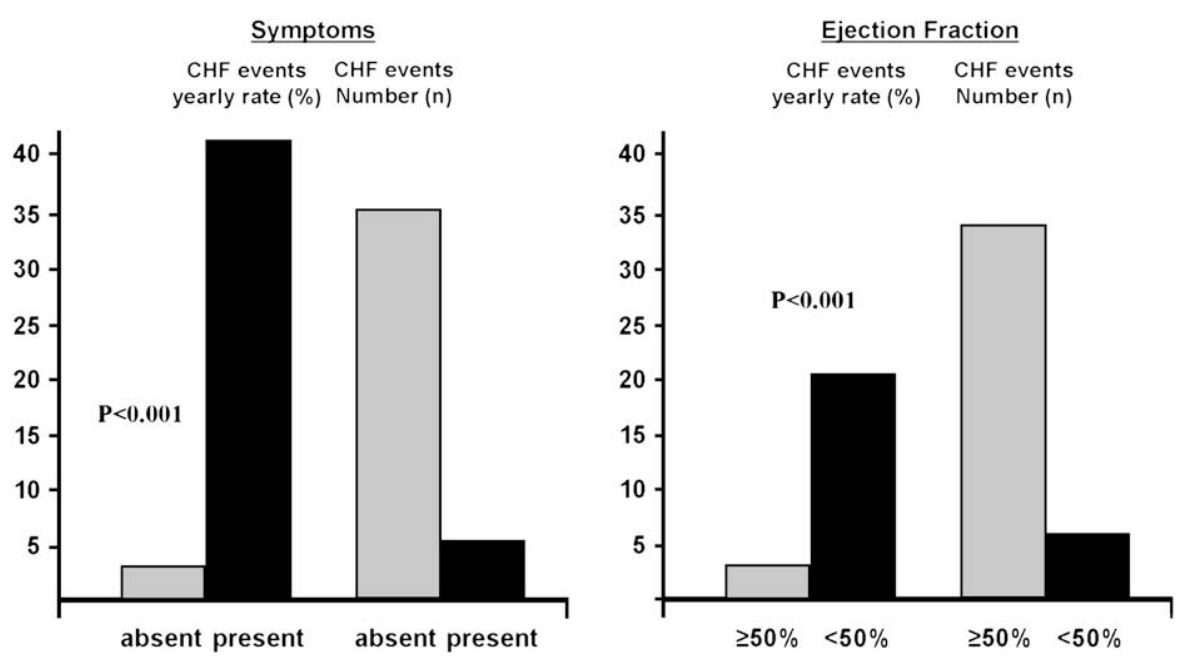

FIGURE 3. Linearized yearly rate of congestive heart failure (CHF; left histograms) and number of CHF events (right histograms) observed according to stratification by the presence or absence of symptoms at baseline (left panel) or by baseline ejection fraction of $50 \%$ or greater or less than $50 \%$ (right panel). Note the high yearly rate of CHF in the subsets with symptoms or an ejection fraction of less than $50 \%$ at baseline but also the low actual number of CHF events in these subsets, demonstrating the low sensitivity of these predictors.

per 100 patient-years), but lack sensitivity. Conversely, QASE grading and an ESVI of $45 \mathrm{~mL} / \mathrm{m}^{2}$ or greater are associated with less striking CHF rates (6-9 per 100 patient-years) but are more sensitive. In these high-risk quantitatively defined subsets, cardiac surgery markedly reduces CHF risk without excess postoperative mortality. Thus rescue operations in patients with traditional surgical markers (symptoms and $\mathrm{EF}<50 \%$ ) should be emphasized but are not sufficient in view of the mediocre postoperative outcome of these patients. In contrast, quantitative echocardio-

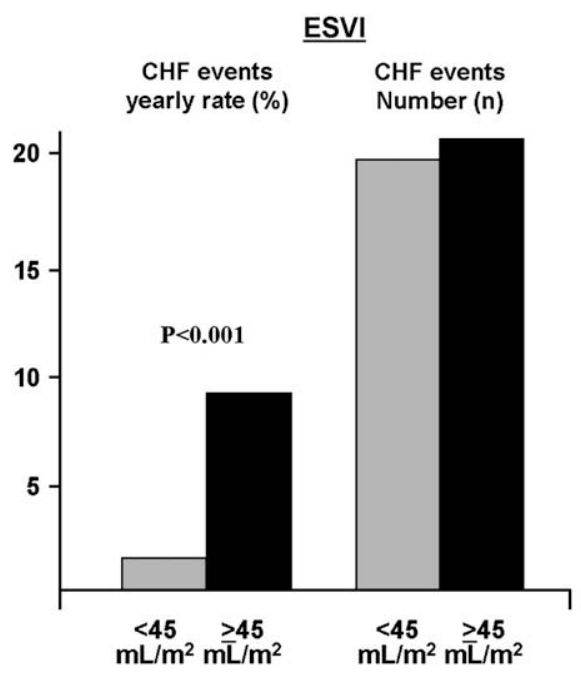

graphic indices allow restorative indications of surgical intervention for $\mathrm{AR}$, which reduces $\mathrm{CHF}$ risk without excess mortality.

\section{Rationale of the Study}

In patients with isolated $\mathrm{AR}, \mathrm{CHF}$ development has been insufficiently studied. Rates of CHF complicating AR are rarely mentioned, ${ }^{2}$ and most often composite end points were the main measures of outcome. ${ }^{3,4,22}$ Thus rates and predictors and effect on outcome of CHF are unclear. ${ }^{2-5}$ These

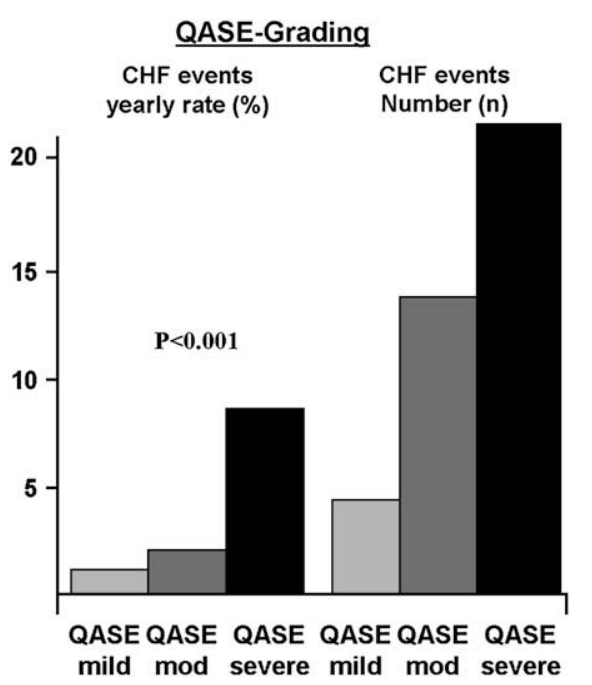

FIGURE 4. Linearized yearly rate of congestive heart failure (CHF; left histograms) and number of CHF events (right histograms) observed according to stratification by end-systolic volume index (ESVI) greater than and less than $45 \mathrm{~mL} / \mathrm{m}^{2}$ (left panel) or by quantitative American Society of Echocardiography (QASE) AR grading (right panel). QASE severe AR is defined as a regurgitant volume of $60 \mathrm{~mL} /$ beat or greater or an effective regurgitant orifice area of 30 $\mathrm{mm}^{2}$ or greater, QASE mild AR is defined as a regurgitant volume of less than $30 \mathrm{~mL} /$ beat and an effective regurgitant orifice area of less than $10 \mathrm{~mm}{ }^{2}$, and QASE moderate AR as greater than QASE mild criteria (regurgitant volume $\geq 30 \mathrm{~mL} /$ beat or effective regurgitant orifice area $\geq 10 \mathrm{~mm}^{2}$ ) but not reaching QASE severe criteria. Note the high CHF rates in the subsets with ESVIs of $45 \mathrm{~mL} / \mathrm{m}^{2}$ or greater or QASE severe AR but also the high actual number of CHF events in these subsets, demonstrating the high sensitivity of these predictors. 
differences might result from patient selection but also from differences in AR severity that might not have been uncovered by using the crude noninvasive AR assessment available at the time. ${ }^{2-5}$

Most importantly, AR management is essentially guided by traditional surgical markers (symptoms or low EF), ${ }^{1}$ and a strategy of symptom-guided management was emphasized as safe and most appropriate for patients with isolated AR. ${ }^{23}$ However, other studies raised concerns regarding outcome with this strategy, even after surgical correction. ${ }^{8,10}$ Thus doubts remain on the respective value of traditional surgical markers (symptoms or low EF) and emerging quantitative measures. Quantitative echocardiography ${ }^{6,19}$ measures absolute AR degree (RVol or ERO) and LV volumes and in our experience is useful in asymptomatic patients ${ }^{12}$ in contrast to the rudimentary methods previously available, ${ }^{1,9}$ but its predictive and management values, relative to symptoms and $\mathrm{EF}$, are undefined.

\section{CHF and AR}

In this prospective study we observed that CHF occurs relatively frequently overall (5.2 per 100 patient-years $)^{2}$ but with considerable differences between subsets of patients. Patients with QASE mild AR rarely incur CHF, whereas other subsets incur much higher rates. We found that baseline symptoms, LV characteristics, and quantified severity of AR independently predict CHF. Symptoms and an EF of less than $50 \%$ are known to influence outcome and are listed in current guidelines. ${ }^{1,9}$ However, the link to outcome is not sufficient, and it is essential to analyze sensitivity and specificity of $\mathrm{CHF}$ prediction in clinical practice. $\mathrm{CHF}$ in $\mathrm{AR}$ has been linked to reduced $\mathrm{EF},{ }^{24}$ and indeed, we also observe that an EF of less than $50 \%$ predicts high CHF rates. Reduced EF also predicts lower survival with medical management ${ }^{2}$ and is considered a strong indication of surgical intervention. ${ }^{1,9}$ Similarly, baseline symptoms, which are known to affect survival, ${ }^{2}$ are associated in our study with high CHF rates, despite improvement with medical treatment. However, outcome with these traditional surgical markers raises several concerns. First, despite existing guidelines, ${ }^{1,9}$ in routine clinical practice surgical intervention for patients with these traditional surgical markers is often delayed, leading to frequent $\mathrm{CHF}$ and excess mortality. Second, in agreement with previous surgical series, ${ }^{10,11,25}$ excess mortality follows operations performed for symptoms or reduced EF, which represent late indicators of rescue operations rather than restorative operations conducive to favorable postoperative outcomes. $^{13}$ Third, symptoms and low EF are insufficient ${ }^{23}$ because they are insensitive and detect only a small minority of the CHF events to come. Therefore in view of the excess mortality after $\mathrm{CHF}$ and of the reduction of $\mathrm{CHF}$ risk by AR surgery, our data unquestionably show that additional predictors of outcome are needed to more sensitively predict CHF events and poor outcome.
Our results verify the hypotheses that quantitative echocardiography provides objective indices (quantitative AR grading and ESVI) that can alleviate the CHF burden in patients with AR. These measures independently predict $\mathrm{CHF}$ incrementally to symptoms and EF and with higher sensitivity. In high-risk patients examined by using quantitative measures, surgical intervention for AR is not associated with excess mortality (as it is for symptoms and low EF) and reduces the risk of $\mathrm{CHF}$.

Although qualitative AR degree predicts $\mathrm{CHF}$, it is superseded by quantitative grading, emphasizing the importance of the quantitative approach. ${ }^{6}$ Our prospective data show that QASE severe AR is the most sensitive CHF predictor, filling a demand unmet by other outcome predictors. ${ }^{13}$ Low CHF rates with QASE mild AR probably represent the background population $\mathrm{CHF}$ rate, which is inconsistently associated with low EF. ${ }^{26}$ In contrast to this background rate, QASE severe AR multiplies CHF risk between 3 and 6 times. LV volume measurements provide another important independent $\mathrm{CHF}$ predictor. End-systolic LV characteristics predict outcome under medical management ${ }^{2,4}$ and after surgical intervention. ${ }^{27}$ Importantly, ESVI supersedes LV diameters (even adjusted for body surface area) and is more sensitive than EF; that is, the measures currently in clinical guidelines $^{1,2,27}$ and an ESVI of $45 \mathrm{~mL} / \mathrm{m}^{2}$ or greater apply equally to men and women by normalizing to body size. ${ }^{21}$

Thus this prospective study contrasts value and complementarity of traditional surgical markers (symptoms and $\mathrm{EF})$, specific and associated high CHF rates, and novel quantitative echocardiographic measures (QASE grading and ESVI), both sensitive and incremental. Because these markers carry different implications for postoperative outcome, they emphasize different clinical implications.

\section{Clinical Implications}

Patients with traditional surgical markers (symptoms or $\mathrm{EF}<50 \%$ ) are at high and immediate risk of CHF or death, irrespective of apparent improvements with medical treatment, but disappointingly, surgical intervention is often delayed. Thus our study emphasizes the need for speedy rescue operations for patients with these ominous characteristics. In view of excess postoperative mortality in these patients, rescue operations should not be the preferred timing of surgical correction of AR.

Quantitative echocardiographic variables allow restorative surgical intervention without excess postoperative mortality and with $\mathrm{CHF}$ risk reduction. Quantitative AR grading predicts $\mathrm{CHF}$ independently of all other clinical characteristics incrementally to traditional surgical markers and supersedes qualitative AR grading. Hence quantitative AR assessment should be encouraged and generalized. ${ }^{6}$

Patients with both QASE severe AR and an ESVI of 45 $\mathrm{mL} / \mathrm{m}^{2}$ or greater incur a progressive but high risk, ${ }^{12}$ particularly of CHF. These characteristics represent the optimal 
target for consideration of surgical correction of AR with low postoperative mortality and marked CHF reduction and thus with the potential to provide true restorative surgical intervention.

Subsets with isolated QASE severe AR or an ESVI of 45 $\mathrm{mL} / \mathrm{m}^{2}$ or greater (but not both) or those with QASE moderate $\mathrm{AR}$ are at moderate CHF risk but might progress and should be monitored closely. Vasodilators for preventing AR progression are disputed, ${ }^{28,29}$ and there is no defined process to stabilize AR or LV function in such patients.

\section{Limitation of the Study}

The occurrence of CHF is complex and implies multiple pathways, and a causal link between AR and CHF is difficult to prove. Coronary artery disease and atrial fibrillation can contribute to $\mathrm{CHF},{ }^{30,31}$ but in the current study they were not independently predictive. Our scope was not to address all possible CHF contributors but to focus on AR-specific CHF prediction. ${ }^{26}$ The link between AR and CHF is supported by strong association of CHF rates with AR degree and by considerable CHF risk reduction after surgical intervention for AR.

Inclusion of baseline symptoms or an EF of less than 50\% might be disputed in that guidelines recommend surgical intervention in such patients. However, our study shows that in clinical practice physicians inconsistently refer such patients to surgical intervention, with delays causing CHF events and death. Thus it is essential to emphasize the need for speedy rescue operations in such patients. The new observation that symptoms and $\mathrm{EF}$ are specific but insensitive in predicting CHF in comparison with objective measurements, such as QASE grading and ESVI, could only be revealed by means of inclusion, irrespective of symptoms or EF, of all patients prospectively examined.

\section{CONCLUSION}

This prospective cohort of patients with AR shows that CHF is frequent after diagnosis and is followed by excess mortality. Traditional surgical markers (symptoms and $\mathrm{EF}<50 \%$ ) predict CHF but are insensitive, and rescue operations are often delayed and associated with excess mortality. QASE severe AR and an ESVI of $45 \mathrm{~mL} / \mathrm{m}^{2}$ or greater independently predict $\mathrm{CHF}$ and provide incremental and sensitive prediction of risk for CHF or for CHF or death. Surgical intervention for AR markedly reduces CHF risk without excess postoperative mortality in these high-risk patients with AR and should be carefully considered in clinical practice.

\section{References}

1. Bonow RO, Carabello BA, Kanu C, de Leon AC Jr, Faxon DP, Freed MD, et al. ACC/AHA 2006 guidelines for the management of patients with valvular heart disease: a report of the American College of Cardiology/American Heart Association Task Force on Practice Guidelines (writing committee to revise the 1998 "Guidelines for the management of patients with valvular heart disease"): devel- oped in collaboration with the Society of Cardiovascular Anesthesiologists: endorsed by the Society for Cardiovascular Angiography and Interventions and the Society of Thoracic Surgeons. Circulation. 2006;114:e84-231.

2. Dujardin KS, Enriquez-Sarano M, Schaff HV, Bailey KR, Seward JB, Tajik AJ. Mortality and morbidity of aortic regurgitation in clinical practice. A long-term follow-up study. Circulation. 1999;99:1851-7.

3. Bonow R, Lakatos E, Maron B, Epstein S. Serial long-term assessment of the natural history of asymptomatic patients with chronic aortic regurgitation and normal left ventricular systolic function. Circulation. 1991;84:1625-35.

4. Borer J, Hochreiter C, Herrold E, Supino P, Ascherman M, Wencker D, et al. Prediction of indication for Valve replacement among asymptomatic or minimally symptomatic patients with chronic aortic regurgitation and normal left ventricular performance. Circulation. 1998;97:525-34.

5. Tornos MP, Permanyer-Miralda G, Evangelista A, Worner F, Candell J, Garcia-del-Castillo $\mathrm{H}$, et al. Clinical evaluation of a prospective protocol for the timing of surgery in chronic aortic regurgitation. Am Heart J. 1990;120:649-57.

6. Zoghbi WA, Enriquez-Sarano M, Foster E, Grayburn PA, Kraft CD, Levine RA, et al. Recommendations for evaluation of the severity of native valvular regurgitation with two-dimensional and Doppler echocardiography. J Am Soc Echocardiogr. 2003; 16:777-802.

7. Spagnuolo M, Kloth H, Taranta A, Doyle E, Pasternack B. Natural history of rheumatic aortic regurgitation. Criteria predictive of death, congestive heart failure, and angina in young patients. Circulation. 1971;44:368-80.

8. Turina J, Hess O, Sepulcri F, Krayenbuehl H. Spontaneous course of aortic valve disease. Eur Heart J. 1987;8:471-83.

9. Vahanian A, Baumgartner H, Bax J, Butchart E, Dion R, Filippatos G, et al. Guidelines on the management of valvular heart disease: the Task Force on the Management of Valvular Heart Disease of the European Society of Cardiology. Eur Heart J. 2007;28:230-68.

10. Klodas E, Enriquez-Sarano M, Tajik A, Mullany C, Bailey K, Seward J. Optimizing timing of surgery in patients with chronic severe aortic regurgitation: the role of symptoms. J Am Coll Cardiol. 1997;30:746-52.

11. Chaliki HP, Mohty D, Avierinos JF, Scott CG, Schaff HV, Tajik AJ, et al. Outcomes following aortic valve replacement in patients with severe aortic regurgitation and markedly reduced left ventricular function. Circulation. 2002;106: 2687-93.

12. Detaint D, Messika-Zeitoun D, Maalouf J, Tribouilloy CM, Mahoney DW, Tajik AJ, et al. Quantitative echocardiographic determinants of clinical outcome in asymptomatic patients with aortic regurgitation: a prospective study. $J$ Am Coll Cardiol Img. 2008;1:1-11.

13. Enriquez-Sarano M, Tajik AJ. Clinical practice. Aortic regurgitation. $N$ Engl J Med. 2004;351:1539-46.

14. Perry GJ, Helmcke F, Nanda NC, Byard C, Soto B. Evaluation of aortic insufficiency by Doppler color flow mapping. J Am Coll Cardiol. 1987;9:952-9.

15. Ho KK, Anderson KM, Kannel WB, Grossman W, Levy D. Survival after the onset of congestive heart failure in Framingham Heart Study subjects. Circulation. 1993;88:107-15.

16. Charlson M, Pompei P, Ales K, MacKenzie C. A new method of classifying prognostic comorbidity in longitudinal studies: development and validation. J Chronic Dis. 1987;40:373-83.

17. Enriquez-Sarano M, Bailey K, Seward J, Tajik A, Krohn M, Mays J. Quantitative Doppler assessment of valvular regurgitation. Circulation. 1993;87:841-8.

18. Enriquez-Sarano M, Seward J, Bailey K, Tajik A. Effective regurgitant orifice area: a noninvasive Doppler development of an old hemodynamic concept. J Am Coll Cardiol. 1994;23:443-51.

19. Schiller N, Shah P, Crawford M, DeMaria A, Devereux R, Feigenbaum H, et al. Recommendations for quantitation of the left ventricle by two-dimensional echocardiography. American Society of Echocardiography Committee on Standards, Subcommittee on Quantitation of Two-Dimensional Echocardiograms. J Am Soc Echocardiogr. 1989;2:358-67.

20. Tribouilloy CM, Enriquez-Sarano M, Fett SL, Bailey KR, Seward JB, Tajik AJ. Application of the proximal flow convergence method to calculate the effective regurgitant orifice area in aortic regurgitation. J Am Coll Cardiol. 1998;32:1032-9.

21. Klodas E, Enriquez-Sarano M, Tajik A, Mullany C, Bailey K, Seward J. Surgery for aortic regurgitation in women: contrasting indications and outcomes as compared with men. Circulation. 1996;1996:2472-8.

22. Tornos MP, Olona M, Permanyer-Miralda G, Herrejon MP, Camprecios M, Evangelista A, et al. Clinical outcome of severe asymptomatic chronic aortic regurgitation: a long-term prospective follow-up study. Am Heart J. 1995;130: 333-9. 
23. Tarasoutchi F, Grinberg M, Spina GS, Sampaio RO, Cardoso LF, Rossi EG, et al. Ten-year clinical laboratory follow-up after application of a symptom-based therapeutic strategy to patients with severe chronic aortic regurgitation of predominant rheumatic etiology. J Am Coll Cardiol. 2003;41:1316-24.

24. Kraus F, Dacian S, Hall D, Klein U, Rudolph W. Relationship between symptoms and hemodynamics associated with regurgitant lesions of the aortic or mitral valve. $Z$ Kardiol. 1986;75:137-40.

25. Klodas E, Enriquez-Sarano M, Tajik A, Mullany C, Bailey K, Seward J. Aortic regurgitation complicated by extreme left ventricular dilatation: long-term outcome after surgical correction. J Am Coll Cardiol. 1996; 27:670-7.

26. Owan TE, Hodge DO, Herges RM, Jacobsen SJ, Roger VL, Redfield MM. Trends in prevalence and outcome of heart failure with preserved ejection fraction. $N E n g l$ J Med. 2006;355:251-9.
27. Carabello B, Williams H, Gash A, Kent R, Belber D, Maurer A, et al. Hemodynamic predictors of outcome in patients undergoing valve replacement. Circulation. 1986;74:1309-16.

28. Evangelista A, Tornos P, Sambola A, Permanyer-Miralda G, Soler-Soler J. Longterm vasodilator therapy in patients with severe aortic regurgitation. $N$ Engl J Med. 2005;353:1342-9.

29. Scognamiglio R, Rahimtoola SH, Fasoli G, Nistri S, Dalla Volta S. Nifedipine in asymptomatic patients with severe aortic regurgitation and normal left ventricular function. N Engl J Med. 1994;331:689-94.

30. Villari B, Campbell S, Hess O. Influence of collagen network on left ventricular systolic and diastolic function in aortic valve disease. J Am Coll Cardiol. 1993;22: 1477-84.

31. Ramsdale D, Bray C, Bennett D, Ward C, Beton D, Faragher E. Routine coronary angiography is unnecessary in all patients with valvular heart disease. $Z$ Kardiol. 1986;75:61-7. 